We have never suggested that, in Zimbabwe, spiritual causes are unrelated to depression. This would be a ridiculous assertion for a culture which holds life to be controlled by the spirits of one's dead ancestors. However, in trying to counteract taboos among the public about psychological disorder it was useful to distinguish between depression and the most well known and feared form of mental illness, akin to the Western category of acute psychosis, which is viewed as caused by a specific form of alien spirit possession.

Neither was it suggested that management guidelines developed in Harare could simply be transported elsewhere. The point of health systems research is that the process of involving local people is the model. We cannot understand why this process could not be used in rural areas to generate appropriate interventions.

Patel found three-quarters of attenders with conspicuous morbidity to be turning to traditional care providers. We welcome his call for their involvement in treatment programmes. Analysis of our cases drawn from a population sample (in preparation), shows only one-fifth had consulted traditional healers, with most turning to family members or the church. Some of the poorest had also struggled to pay for private doctors, operating outside the government clinics. Successful intervention programmes need to take into account the variety of agencies that people choose to turn to. LUTZ, C. (1985) Depression and translation of emotional worlds.
In Culture and Depression: Studies in the Anthropology
and Cross-Cultural Psychiatry of Affect and Disorder (eds A.
Kleinman \& B. Good). Berkeley: University of California Press.

Institute of Psychiatry

Melanie Abas

London SE5 8AF

Maudsley Hospital

London SE5 8AZ

Department of Psychiatry

GeRTRUde KhUMaslo-SAKatUKWa University of Zimbabwe

\section{Chromosomal aberration and bipolar affective disorder}

SIR: Craddock \& Owen (BJP, April 1994, 164, 507-512) state that no literature review has suggested an increased rate of bipolar disorder to be associated with the possession of an extra $X$ chromosome. However a recent review (Everman \& Stoudemire, 1994) does reach this conclusion.
Reporting a patient with bipolar disorder and previously undiagnosed Klinefelter's syndrome, Everman \& Stoudemire state that this is the 14th recorded instance of such an association and note three other cases of bipolar illness in individuals with other $\mathrm{X}$ chromosome excesses (two with $\mathrm{XO} /$ $\mathrm{XX} / \mathrm{XXX}$ mosaicism and one with $\mathrm{XXX}$ syndrome). Two of their cases are included in Craddock \& Owen's table 1 but a further 15 (13 with cytogenetic confirmation of an extra $X$ ) are not. The addition of these cases makes the ratio of $\mathrm{X}$ chromosome relative to autosomal abnormalities more impressive, in agreement with Everman \& Stoudemire's conclusion that there is some support in cytogenetic studies for a theory of $\mathrm{X}$ linkage.

If both bipolar disorders and schizophrenia (Crow, 1988; DeLisi et al, in press) are found in excess in individuals with an extra $\mathbf{X}$ chromosome this adds support to the concept of a continuum of psychosis (Crow, 1986) with a single genetic locus on the $X$, perhaps counter-balanced by one on the $Y$ chromosome.

CRow, T. J. (1986) The continuum of psychosis and its implication for the structure of the gene. British Journal of Psychiatry, 149, $419-429$.

- (1988) Sex chromosomes and psychosis: the case for a pseudoautosomal locus. British Journal of Psychiatry, 153, 675-683.

DeLISI, L. E., FrIEDRICH, U., WAHLSTROM, J., et al (1994) Schizophrenia and sex chromosome abnormalities. Schizophrenia Bulletin (in press).

Everman, D. B. \& Stoudemme (1994) A bipolar disorder associated with Klinefelter's syndrome and other chromosomal abnormalities. Psychosomatics, 35, 35-40.

Medical Research Council

T. J. Crow

Watford Road

Harrow HAl 3UJ

\section{Genetics, chance and dysmorphogenesis in} schizophrenia

SIR: McGuffin et al (BJP, May 1994, 164, 593-599) emphasise the prominence of the genetic contribution to schizophrenia and examine in detail four hypotheses as to the relative roles of genes and environment in the origins of the disorder. In evaluating their fourth and most radical hypothesis, they argue that apparently 'non-genetic' components may be random changes in gene structure and expression, but fail to note an earlier formulation thereon that also relates importantly to contemporary perspectives of schizophrenia as a neuro-developmental disorder.

That chance may in part determine differences in brain development, even in the face of genetic 